\title{
Towntology \& hydrOntology: Relationship between Urban and Hydrographic Features in the Geographic Information Domain
}

\author{
Luis Manuel Vilches Blázquez¹, Miguel Ángel Bernabé Poveda², Mari Carmen \\ Suárez-Figueroa ${ }^{3}$, Asunción Gómez-Pérez ${ }^{4}$, Antonio Federico Rodríguez Pascual ${ }^{5}$ \\ ${ }^{1,5}$ Instituto Geográfico Nacional. General Ibáñez de Íbero, 3. 28003 Madrid. Spain. \\ \{lmvilches,afrodriguez\}@fomento.es \\ ${ }^{2}$ E.T.S.I. en Topografía, Geodesia y Cartografía. Universidad Politécnica de Madrid, Km \\ 7.5 de la Autovía de Valencia. 28031 Madrid. Spain. \{ma.bernabe@upm.es\} \\ ${ }^{3,4}$ Facultad de Informática. Universidad Politécnica de Madrid. Campus de Montegancedo, \\ s/n. 28660 Boadilla del Monte. Madrid. Spain. \{mcsuarez,asun\}@fi.upm.es
}

\begin{abstract}
This article describes the relationship between Urban Civil Engineering and other domains, specifically the hydrographic domain. The process of building HydrOntology and the portion of the model relating to urban features are described. This ontology emerges with the intent of settling as a framework in the GI domain, very closely interrelating to Towntology.
\end{abstract}

Keywords: GI (Geographic Information), Geographic Information System, Spatial Data Infrastructure, Ontological Framework, METHONTOLOGY.

\section{Introduction}

Hydrography and related phenomena represent an essential part of reality in our cities as a consequence of the water supply needs they all have. This is going to characterize some aspects of city planning, owing to the presence of water infrastructures and to the addition of certain hydrographic phenomena in urban landscapes. This fact reflects the analogy of cities and other knowledge domains that, in view of their close relationship, are not irrelevant to the development of ontologies in the domain of Urban Civil Engineering. For that, a close collaboration between different scientific fields and disciplines is required, including civil engineering, urban design and planning and spatial information techniques [16]

These circumstances lead into an enhanced knowledge, since the use and development of ontologies are aroused in any domain Urban Civil Engineering projects are related to. This interrelation between different domains should contribute to enhancing access to GI.

Nowadays, in our society, the demand of GI is becoming a foremost need. Due to the poor, not well organized structure of GI as provided by the cartographic agencies, we 
2 Luis Manuel Vilches Blázquez1, Miguel Ángel Bernabé Poveda2, Mari Carmen Suárez-

Figueroa3, Asunción Gómez-Pérez4, Antonio Federico Rodríguez Pascual5

come across many problems in the successful search and retrieval of data. These problems mainly arise because each community producer is typically focused on specific needs [13]. That means that a harmonisation between the different agencies has not been achieved.

The development of Ontological Engineering is a key matter in the solution of current problems related to GI access and in distributed search in different cartographic organizations. For that reason, the definition of an ontological framework in the achievement of an easy accessibility and common structure of data becomes necessary. That means to provide a certain structure of names, codes, attributes and other associated represented characteristics being responsible for defining the real world. Thus, in order to give an answer to Society, these interrelated ontological frameworks (hydrOntology and Towntology) will hopefully improve the structure of the world of classical cartography, computer-assisted GIS (Geographic Information System) and SDI (Spatial Data Infrastructure).

With regard to hydrOntology, its purpose is to serve as a harmonization framework among the Spanish cartographic producers, trying to disseminate it internationally, making it available to GI producers. With this ontology we intend to provide the necessary steps to obtain a better organization and management of the hydrological features, which are spread over into the different projects, documents and directives in this field. To this information we should add a great number of catalogues, data dictionaries and so on due to the existence of different producers of GI. Another important characteristic is the different geometrical representation of the same domain (point, line, surface).

In section 2 of this paper, we describe the relationship between urban and hydrographic features. In section 3 we describe the problems encountered and characteristics of the integration process of the GI. Besides that, the semantic differences are commented in section 4. In section 5, the different ontological structure criteria are also commented, while, in section 6 the characteristic of the building up this hydrOntology through the use of METHONTOLOGY $[1,2]$ it is also given. Finally, in section 7, several conclusions and some future research lines are indicated.

\section{Relationship between Urban and Hydrographic Features}

Describing the richness of the urban environment in full detail represents a great challenge since this environment is very complex. It contains some natural occurrences like rivers that are features with natural boundaries. However, the urban environment is essentially made up of artificial objects. Even features such as rivers, when crossing urban environments, have their boundaries shaped by people and can be considered as artificial objects [19]. 
Towntology \& hydrOntology: Relationship between Urban and Hydrographic Features in the Geographic Information Domain 3

The change of hydrographic features into artificial objects is the result of the building of urban infrastructures for water supply, distribution and clean-up. Below three cases are shown where the close relationships between urban and hydrographic features are revealed.

i. The river feature has often been a key factor in the configuration of city maps. Because of this fact, urban infrastructures surrounding or being a part of this feature are common. Actually we find retaining walls in river banks for canalization in a widespread fashion. Building of bridges as roads or passage ways between river banks is usual.

ii. The water mains (piping) play a key role in the water supply, distribution and clean-up. Part of the mains are used for drinking water in the urban environment while another part of the pipes are utilized for residual waters that are channelled down to treatment plants for recycling and other uses.

iii. Finally the sewer system and the rain water drains are most important for the urban environment owing to the fact that they take care of the removal of water from rainfalls or riverbed floods. Their efficient operation diminishes the effects of previous meteorological mishaps.

The close relationship between the features of both domains and consequently, the linking between these ontologies (Towntology and HydrOntology) will facilitate reaching the Towntology Project's aims. These are [17]:

- To identify terms and concepts used in different urban activities.

- To organize urban knowledge.

- To facilitate communication between various urban actors manipulating the same object types when achieving different goals.

- To gather urban data provided by heterogeneous sources.

In short, from the viewpoint of applicability, as a result of links between domains, the need to relate them becomes greater. This is due to the fact that, as a consequence of their interrelation, management of one of the utility networks can be set up. This is one of the subjects of INSPIRE $^{1}$, i.e. information referred to water supply and drainage networks (sewers, gutters, drainpipes, etc) could be controlled. Another interesting aspect coming up from the relationship between these two ontologies is the prevention of certain natural hazards affecting urban environments. Floods would thereby better managed and monitored due to the possibility of implementing applied hydrology models (estimation of maximum flows in the hydrographic network by means of empirical models) and through drainage models in cities in the face of unusually heavy rainfalls (statistical models).

${ }^{1}$ http://www.ec-gis.org/inspire/ 
4 Luis Manuel Vilches Blázquez1, Miguel Ángel Bernabé Poveda2, Mari Carmen SuárezFigueroa3, Asunción Gómez-Pérez4, Antonio Federico Rodríguez Pascual5

\section{Integration of Geographic Information}

The basic unit of GI within most models is the 'feature', where by feature we mean an abstraction of a real world phenomenon, a geographic feature being a feature associated with a location on the earth [10]. Features can include representations of a wide range of phenomena that can be located in time and space such as buildings, towns and villages or a geometric network, geo-referenced image, pixel, or thematic layer. This means that traditionally a feature encapsulates all that a given domain considers about a single geographic phenomenon in one entity [9].

Features can be considered at two levels: feature instances and feature types. Feature instances are the individual discrete representations of geographic phenomena in a database with geographic and temporal dimensions. The instances may then be grouped into classes with common characteristics to form feature types. However, in Open Geospatial Consortium terms features are not fixed in their class but have application-oriented views that are classed [10] i.e. depending on the domain classification, a feature instance may be classified one way or another. Therefore, it is apparent that features are not the atomic units of GI as the phenomena they represent, encapsulating different human concepts resulting in multiple types [9]. This is the case of the hydrological domain, since there are different cartographic producers with various degrees of quality and structuring of information. That means a coexistence of a great variety of sources with different information and structure without a general harmonization framework.

In addition a scale factor should also be included which acts as a filter in the cartographic representation such as catalogues and dictionaries in the hydrological domain. For this reason, we have to consider information at several scales (local, regional and national) in the hydrOntology, though we are aware of the fact that indepth work in the hydrographic features of cities should be carried out, owing to the change in geometric and semantic resolutions brought about by the scale difference between both domains. Moreover, some problems related with language ambiguity should be added, such as polysemy, synonymy, hyperonymy and homonymy present in many concepts in this domain.

An added drawback in the creation of hydrOntology has been the scarce semantic information present in many information sources consulted (EuroGlobalMap, EuroRegionalMap, DGIWG group FACC codes (Feature Attribute Code Catalogue), Numerical Cartographic Database to scale 1:200.000 and 1:25.000 of Instituto Geográfico Nacional of Spain (IGN-E), feature catalogues of Spanish cartographic producers, Geographic Gazetteer (IGN-E), etc. This information is of fundamental importance to distinguish and compare features in any knowledge domain.

Consideration of these facts has left a trace in the modelling process of this ontology framework of hydrographic features by trying to solve recurrent problems and contribute to shared knowledge. 
Towntology \& hydrOntology: Relationship between Urban and Hydrographic Features in the Geographic Information Domain 5

\section{Semantic Differences}

The existing semantic differences in some domains are numerous, and this is so in the hydrographic domain, where several meanings and concepts are encountered. A repetitive example in this knowledge domain is the river definition. The Water Framework Directive (WFD) defines a river feature as "a body of inland water flowing for the most part on the surface of the land but which may flow underground for part of its course" [11], while the Ordnance Survey defines it as "water flowing in a definite channel towards the sea, a lake or into another river" [12]. On the other hand, the IGN-E considered the river a "natural freshwater stream". Nowadays, the IGN-E has decided to adopt the WFD proposal because it is a continuous phenomenon, although it would lack a cartographic representation when the flowing occurs underground.

Due to the diversity in semantic concepts within the domain, the definition of the characteristics and the context has been restricted, adapting it to the topographic data base, as the Numerical Cartographic Database of IGN-E. Every definition will take the cartographic representation into account through map, GIS or SDI, no matter what the intrinsic reality of these phenomena is.

Furthermore, in the hydrOntology development we have taken into account some concepts about feature capture which depend exclusively on different geographic regions, since they are concepts related to their importance in both Geography and Cartography. Among these features appear "ibón", "lavajo", "chortal", "bodón" and "lucio". These concepts are designated by their local name and they are synonymous to the feature "Charca" , i.e. a small lake of shallow water. Later, we will analyse other international GI catalogues and dictionaries, adding further concepts of this kind to enrich this ontology.

Finally, due to the mapping purpose of this ontology to other knowledge bases (Thesaurus of UNESCO ${ }^{3}$, Alexandria Digital Library ${ }^{4}$, Thesaurus GEMET ${ }^{5}$, Getty Thesaurus of Geographic Names ${ }^{6}$, etc.) several features are considered which will be used to relate to other domains, such as the legal framework (international law). Concepts like "territorial waters", "contiguous zone", "high seas", etc., or the geological domain (hydrogeology) "underground currents", "aquifers", etc. may be considered as an example.

\footnotetext{
${ }^{2}$ The above mentioned terms are Spanish local names.

${ }^{3} \mathrm{http}: / / \mathrm{www} 2 . \mathrm{ulcc}$.ac.uk/unesco/

${ }^{4} \mathrm{http}: / /$ www.alexandria.ucsb.edu/

${ }^{5} \mathrm{http}: / / \mathrm{www}$.eionet.europa.eu/GEMET

${ }^{6} \mathrm{http} / / /$ www.getty.edu/research/conducting_research/vocabularies/tgn/
} 
6 Luis Manuel Vilches Blázquez1, Miguel Ángel Bernabé Poveda2, Mari Carmen SuárezFigueroa3, Asunción Gómez-Pérez4, Antonio Federico Rodríguez Pascual5

\section{Criteria for HydrOntology Structuring}

Taking into account the difficulties related to ontological framework standardization as mentioned above, we propose hydrOntology as a concurrent model to solve the structuring and harmonization problems for the GI community.

The organization present in this ontology about hydrographic features is governed mainly by four criteria:

1. The European Directive to set up a communitarian frame of performance in the scope of the water policy (WFD) [11]. Precisely, in article 2, a list of hydrographic phenomena definitions is given which may be considered as an implicit classification. That contributes to the modelling of more abstract features that make up the hydrOntology taxonomy. The definitions of hydrographic phenomena gathered in this article are proposed by the European Parliament and the European Union Council which makes such proposals mandatory in any taxonomy within this domain.

2. On the other hand, as a consequence of the aim of implementation of this ontology in the SIGNA-E and in the IDEE, we are taking into consideration the classification worked out by the SDIGER Project ${ }^{7}$ [18], [an SDI created to support the access to GI resources concerned with the WFD within an inter-administration and cross-border scenario that involves two countries, France and Spain as well as the two main river basin districts on both sides of the border, the Adour-Garonne basin district, managed by the Water Agency for the Adour-Garonne River Basins ${ }^{8}$ (L'Agence de l'Eau Adour-Garonne) and the Ebro river basin district, managed by the Ebro River Basin Authority ${ }^{9}$ (Confederación Hidrográfica del Ebro)]. That project was chosen by Eurostat $^{10}$ as a pilot project of the applicability of INSPIRE.

In addition to those documents [14], the development of hydrOntology's modelling such as UML models [15] from the above mentioned SDIGER project have a strategic importance. In the phase of analysis those models were adopted and several changes were included reaching a consensus with the Working Group of the University of Zaragoza. Those changes upgrade the proposed models.

3. Being aware of the importance of the establishment of a taxonomical order, several semantic criteria have been added. Thus the hydrographic feature classification is in accordance with the meaning of each feature.

4. Finally, an important matter should be added to those criteria, namely the presence of the inheritance of different sources in the modelling of this ontology, on the one

\footnotetext{
${ }^{7} \mathrm{http} / / / \mathrm{www}$. idee.es/sdiger/

${ }^{8} \mathrm{http}: / /$ www.eau-adour-garonne.fr

${ }^{9} \mathrm{http}: / / \mathrm{www}$. chebro.es/

${ }^{10} \mathrm{http}: / /$ epp.eurostat.cec.eu.int/portal/page?_pageid=1090,30070682,1090_33076576\&_dad=po rtal\&_schema=PORTAL
} 
Towntology \& hydrOntology: Relationship between Urban and Hydrographic Features in the Geographic Information Domain 7

hand to facilitate the possible information mapping and on the other to be consequent with the hierarchy of the features carried out by the expert in the domain.

\section{Characteristics of HydrOntology Development Process}

The development of hydrOntology has been based on METHONTOLOGY which was developed within the Ontological Engineering Group (OEG) ${ }^{11}$ at Universidad Politécnica de Madrid. This methodology enables the development of ontologies at the knowledge level, and has its roots in the main activities identified by the IEEE software development process [3] and in other knowledge engineering methodologies [4].

This methodology (METHONTOLOGY) has been used by different groups to build ontologies in different knowledge domains, such as Chemistry, Science, Knowledge Management, e-Commerce, etc. A detailed description of the methodology of this ontology building can be found in [2].

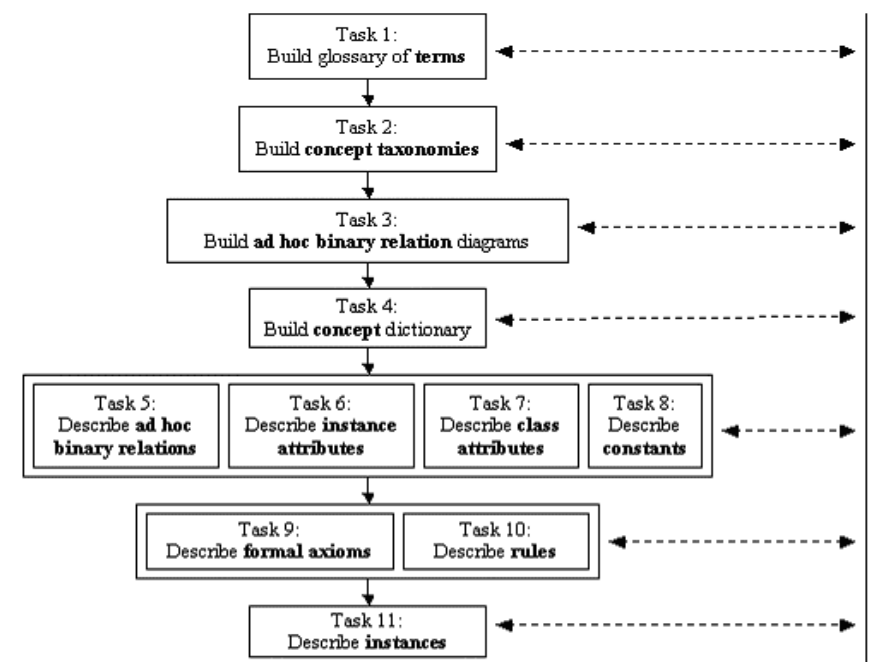

Fig 1. Tasks of the conceptualization activity according to METHONTOLOGY[2].

In order to ensure the HydrOntology consistency and completeness, several steps have been followed. Figure 1 shows the ontology building tasks suggested in the METHONTOLOGY framework [5].

As seen in Figure 1, a glossary of terms was built, as a result of the study of several feature catalogues and data dictionaries (Numerical Cartographic Database of the IGN-E, catalogues and data dictionaries from other cartographic agencies, WordNet,

${ }^{11} \mathrm{http}: / /$ parla.dia.fi.upm.es/oeg/ 
8 Luis Manuel Vilches Blázquez1, Miguel Ángel Bernabé Poveda2, Mari Carmen SuárezFigueroa3, Asunción Gómez-Pérez4, Antonio Federico Rodríguez Pascual5

etc.), thesauri (UNESCO, GEMET, Getty TGN, etc.), the project SDIGER, different classification systems and taxonomies (Alexandria DL, Dewey, etc.), etc., trying to cover the greatest amount of IG sources, in order to build a complete ontological frame. This glossary contains more than 100 relevant concepts related to hydrology as river, reservoir, lake, channel, pipe, water tank, siphon, etc.

In a first approach, a taxonomy of concepts was built. METHONTOLOGY suggests using the four taxonomic relations defined in the Frame Ontology [6] and the OKBC Ontology [7]: Subclass-Of, Disjoint-Decomposition, Exhaustive-Decomposition and Partition.

A concept $\mathrm{C} 1$ is a Subclass-Of another concept C2 if and only if every instance of C1 is also an instance of $\mathrm{C} 2$. [5].

A Disjoint-Decomposition of a concept $\mathrm{C}$ is a set of subclasses of $\mathrm{C}$ that do not have common instances and do not cover $\mathrm{C}$, that is, there can be instances of the concept $\mathrm{C}$ that are not instances of any of the concepts in the decomposition [5]. An example of this type of relationship is shown in Figure 2.

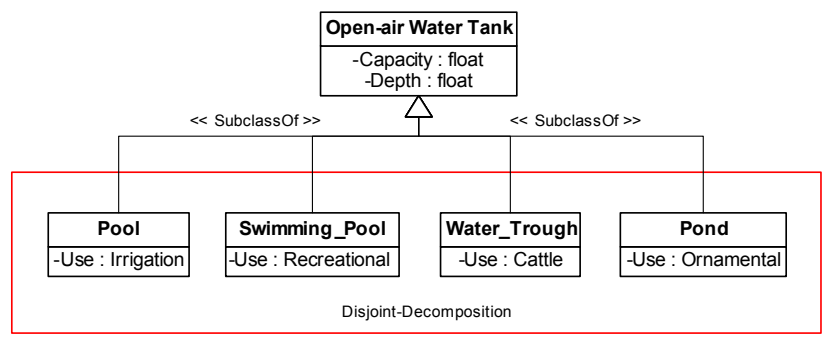

Fig 2. Example of Disjoint-Decomposition included in hydrOntology

An Exhaustive-Decomposition of a concept $\mathrm{C}$ is a set of subclasses of $\mathrm{C}$ that cover $\mathrm{C}$ and may have common instances and subclasses, that is, there cannot be instances of the concept $\mathrm{C}$ that are not instances of at least one of the concepts in the decomposition [5]. Figure 3 shows an example of this type of relationship.

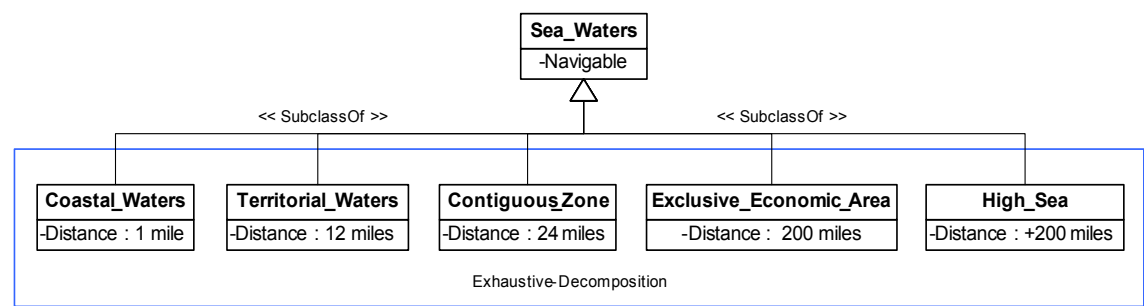

Fig. 3. Example of Exhaustive-Decomposition included in hydrOntology.

A Partition of a concept $\mathrm{C}$ is a set of subclasses of $\mathrm{C}$ that do not share common instances and that cover $\mathrm{C}$, that is, there are not instances of $\mathrm{C}$ that are not instances of 
Towntology \& hydrOntology: Relationship between Urban and Hydrographic Features in the Geographic Information Domain 9

one of the concepts in the partition [5]. An example of a partition is shown in Figure 4.

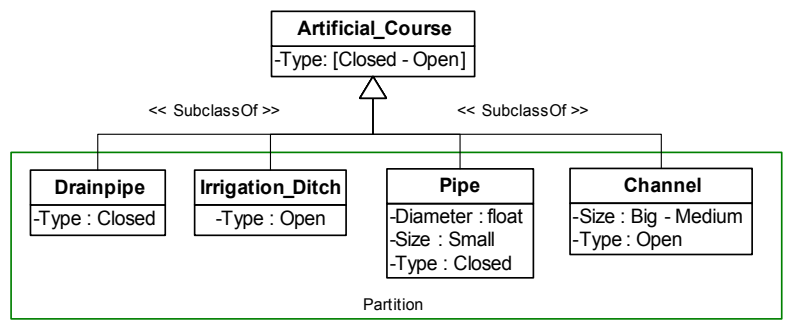

Fig. 4. Example of Partition included in hydrOntology

Once the different taxonomic relationships had been established and due to the absence of semantic information in many of the sources of information considered, a conceptual hydrographic dictionary was constructed. That implies endorsing GI semantics. Among different sources considered in the building of this dictionary we should mention WordNet ${ }^{12}$, Encyclopaedia Britannica ${ }^{13}$, Diccionario de la Real Academia Española de la Lengua ${ }^{14}$, Wikipedia ${ }^{15}$ and several geographical dictionaries. After carrying out those steps, we went through the taxonomy to make sure it did not contain any errors [8]. Moreover, a dictionary was drawn up and used to ensure that the taxonomic organization was semantically consequent.

Once the taxonomy of concepts was correctly structured, an ad-hoc relationship between different ontology concepts was established. The type of relationship and other components explicitly contribute to enrich the hydrOntology. An example of an ad hoc relation is shown in Figure 5.

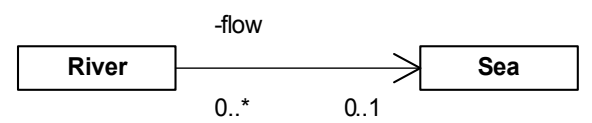

Fig.5. Example of ad hoc relationship included in hydrOntology

Next step in the development of this ontology was the attribute specification for every concept. This is a difficult, subjective task due to the ambiguity and similarity of many real world phenomena. Then a differentiation between instance attributes and those belonging to the classes was applied. The instance attributes are those attributes whose value(s) may be different for each instance of the concept [2]. On the contrary, the class attributes describe concepts and take their value in the class where they are defined [2]. In Figure 2 and Figure 3, a clear example of this type of attributes is shown. On the one hand, in Figure 2 the instance attributes are shown by means of the

\footnotetext{
$12 \mathrm{http}: / /$ wordnet.princeton.edu/

${ }^{13} \mathrm{http} / / / \mathrm{www} \cdot$ britannica.com/

${ }^{14} \mathrm{http}: / / \mathrm{www}$. rae.es

15 http://www.wikipedia.org/
} 
10 Luis Manuel Vilches Blázquez1, Miguel Ángel Bernabé Poveda2, Mari Carmen SuárezFigueroa3, Asunción Gómez-Pérez4, Antonio Federico Rodríguez Pascual5

information related to a specific value for each "distance" in the different subclasses and on the other hand the class attribute "navigable" as a class generic attribute. In Figure 3, the instance attributes are shown by means of the information related to a specific type for each "use", while the class attributes appear in the Open-Air Water Tank Class ("Capacity" and "Depth")

After having carried out the different steps, in view of the obvious implications and alterations involving urban and hydrographic features, the need to relate hydrOntology and Towntology was considered. The relationship between these ontological frameworks facilitates communication between various urban actors, organization and management of knowledge are improved [17] and a way toward a cooperative system is provided, capable of looking at knowledge in a scalar way, with added benefit for the users. Figure 6 shows an example of the relationship between the different urban and hydrographic features.

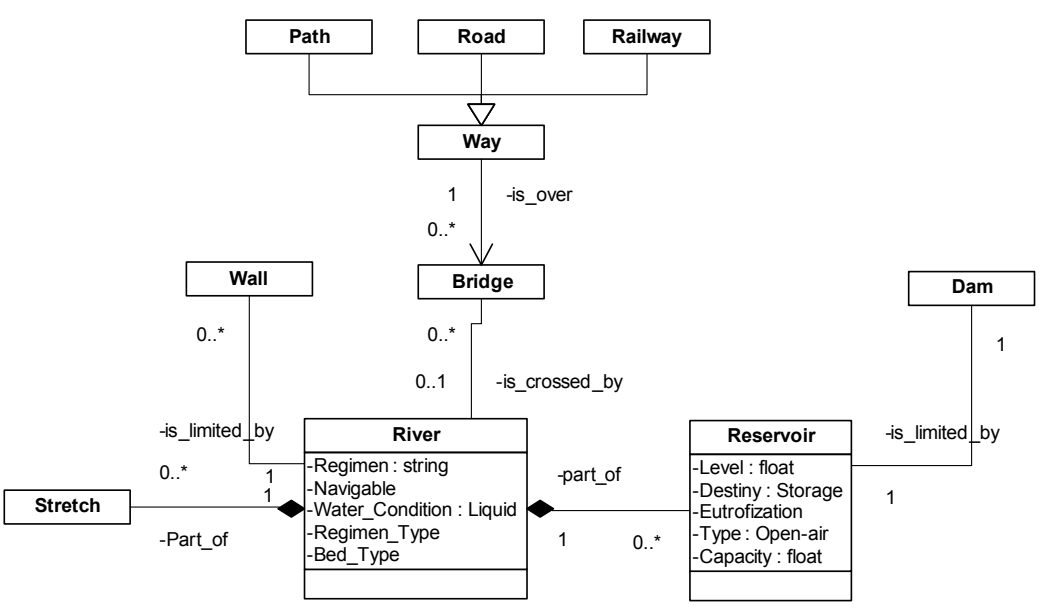

Fig.6. Example of relationship between urban and hydrographic features

Finally once the conceptual modelling process has been taken care of for this ontology, we will try to include instances of different concepts that are part of hydrOntology and Towntology. Those instances will be gathered from the different national cartographic producers.

\section{Conclusions and Future Work}

Reflections on the relationships between Urban Civil Engineering ontologies and other domains become necessary, since a much greater knowledge and applicability are thereby achieved. At the same time these relationships allow promotion and improvement in communication between different information systems as a result of a 
Towntology \& hydrOntology: Relationship between Urban and Hydrographic Features in the Geographic Information Domain 11

better structuring of information, a better establishment of relationships and the possibility of feature mapping.

In this paper, all the different problems which reflect the difficulty to access to the GI are considered. This indicates that further structuring of information is needed as the complexity and volume of data increases. In other words, it is also necessary to have an ontological framework.

Although this ontology is in a stage of development, it constitutes an important headway towards an optimal structuring of semantic information by the spatial data producer organizations.

HydrOntology is also an interesting project in the IGN-E because it improves the information classification and management, in favour of the optimization in the search and recovery of the GI supported by the IDEE and the SIGNA-E. However, it tries to establish it as a generic semantic frame for use of every producer organization. This contributes to the shaping of a common, shared knowledge in the GI domain. With this ontology we think it is possible to define, relate and regulate the features in a unique way once a consensus is reached. We will do away with today's heterogeneity.

The next phase of this work will improve hydrOntology, by means of its enrichment through the implementation of possible rules, axioms and constants. In addition, the instances through compiled information from diverse sources will be added. With these processes, we are trying to draw inferences and a greater knowledge of the domain. We will also establish mapping to different knowledge sources (Digital Alexandria Library, Thesaurus of UNESCO, Wikipedia, etc.) and with ontologies of related domains such as Towntology, thereby extending the information of the features contained in this ontology framework.

Finally, we will analyze a number of feature catalogues and dictionaries from different worldwide organizations. This will serve as a starting point in the hydrOntology adoption as an ontology framework in the GI world.

\section{References}

1. Fernández-López M, Gómez-Pérez A, Juristo N (1997) METHONTOLOGY: From Ontological Art Towards Ontological Engineering. Spring Symposium on Ontological Engineering of AAAI. Stanford University, California, pp 33-40

2. Gómez-Pérez A, Fernández-López M, Corcho O (2003) Ontological Engineering: with examples from the areas of knowledge management, e-commerce and the Semantic Web, Springer-Verlag, New York.

3. IEEE (1996) IEEE Standard for Developing Software Life Cycle Processes. IEEE Computer Society. New York. IEEE Std 1074-1995.

4. Gómez-Pérez A, Juristo N, Montes C, Pazos J (1997) Ingeniería del Conocimiento: Diseño y Construcción de Sistemas Expertos. Ceuta, Madrid, Spain 
12 Luis Manuel Vilches Blázquez1, Miguel Ángel Bernabé Poveda2, Mari Carmen SuárezFigueroa3, Asunción Gómez-Pérez4, Antonio Federico Rodríguez Pascual5

5. Corcho O, Fernández-López M, Gómez-Pérez A, López-Cima (2005) A. Building legal ontologies with METHONTOLOGY and WebODE. Law and the Semantic Web. Legal Ontologies, Methodologies, Legal Information Retrieval, and Applications. SpringerVerlag.

6. Farquhar A, Fikes R, Rice J (1997) The Ontolingua Server: A Tool for Collaborative Ontology Construction. International Journal of Human Computer Studies 46(6):707-727

7. Chaudhri VK, Farquhar A, Fikes R, Karp PD, Rice JP (1998) Open Knowledge Base Connectivity 2.0.3. Technical Report. http://www.ai.sri.com/ okbc/okbc-2-0-3.pdf

8. Gómez-Pérez A (2001) Evaluation of Ontologies. International Journal of Intelligent Systems 16(3):391-409.

9. Greenwood J, Hart G. (2003) Sharing Feature Based Geographic Information - A Data Model Perspective. 7th Int'l Conference on GeoComputation. United Kingdom.

10. OPEN GEOSPATIAL CONSORTIUM, 2003, OpenGIS Reference Model, Version 0.1.2, Open Geospatial Consortium Inc. Wayland, MA, USA.

11. European Parliament and the Council of the European Union. (2000) Directive 2000/60/EC of the European Parliament and of the Council for establishing a framework for Community action in the field of water policy. Brussels, $\mathrm{p} 72$.

12. Ordnance Survey (2001): Master Map real-world object catalogue. http://www.ordnancesurvey.co.uk/oswebsite/products/osmastermap/faqs/Docs/realWorldO bjectCatalogue.pdf

13. Bermudez L, Piasecki M. (2004) Role of Ontologies in Creating Hydrologic Metadata. International Conference on HydroScience and Engineering, Brisbane, Australia.

14. Institute Geographique National France International, Institut Géographique National France, Centro Nacional de Información Geográfica Spain and University of Zaragoza. (2005) Common Model Activity - Final report. SDIGER: A cross-border interadministration SDI to support WFD information access for Adour-Garonne and Ebro River Basins.

http:/www.idee.es/sdiger/public_docs/CommonModelActivity_FinalReport_v0.3.pdf

15. Institut Géographique National France International, Institut Géographique National France, Centro Nacional de Información Geográfica and University of Zaragoza. (2005). SDIGER UML models. http://www.idee.es/sdiger/public_docs/ThemWaterUMLModels.pdf

16. Teller J. , Keita A. K. , Roussey C. , Laurini R. (2005), "Urban Ontologies for an improved communication in urban civil engineering projects", Proceedings of the International Conference on Spatial Analysis and GEOmatics, Research \& Developments, SAGEO 2005 Avignon, France, June, 20th-23rd.

17. Keita A., Laurini R., Roussey C., Zimmerman M. (2004), Towards an Ontology for Urban Planning: The Towntology Project. In CD-ROM Proceedings of the 24th UDMS Symposium, Chioggia, October 27-29, 2004, pp 12.I.1.

18. Latre M.A., Zarazaga-Soria F.J., Nogueras-Iso J., Béjar R., Muro-Medrano P.R. (2005) SDIGER: A cross-border inter-administration SDI to support WFD information access for Adour-Garonne and Ebro River Basins. Proceedings of the 11th EC GI \& GIS Workshop, ESDI Setting the Framework. Alghero, Sardinia (Italy).

19. Fonseca F., Egenhofer M., Davis C.,Borges K. Ontologies and Knowledge Sharing in Urban GIS. CEUS - Computer, Environment and Urban Systems 24 (3) (2000) p 232-251. 